\title{
Pengukuran Frekuensi Gender Barung Laras Slendro Menggunakan Perangkat Lunak SpectraPlus
}

\author{
Santi Nurmalia Nuzul dan Mitrayana*
}

\begin{abstract}
Ringkasan
Penelitian ini bertujuan untuk menganalisa frekuensi karakteristik dari gamelan khususnya Gender Barung Laras Slendro. Gender Barung Laras Slendro merupakan salah satu perangkat gamelan yang belum memiliki standar frekuensi nada seperti pada alat-alat musik modern. Penalaan frekuensi nada pada gamelan dilakukan oleh para ahli secara tradisional dengan cara kira-kira berdasarkan pengalaman dan hanya mengandalkan pendengaran dan perasaan untuk mencocokkan frekuensi nada. Metode tersebut membuat setiap gamelan memiliki frekuensi nada yang tidak seragam. Hasil penelitian ini diharapkan dapat menjadi acuan untuk upaya standarisasi frekuensi nada gamelan khususnya Gender Barung Laras Slendro. Penelitian dilakukan pada tujuh (7) sampel Gender Barung Laras Slendro yang berbeda. Frekuensi diri setiap wilahan diukur dengan cara menabuhnya dengan tekanan yang relatif sama. Secara bersamaan bunyi direkam menggunakan microphone yang dihubungkan ke laptop yang telah dilengkapi perangkat lunak SpectraPlus. SpectraPlus akan menampilkan frekuensi dan spektrum bunyi yang dihasilkan. Data yang terkumpul dianalisa dan diperoleh nilai frekuensi diri setiap wilahan pada tujuh sampel Gender Barung Laras Slendro. Hasilnya menunjukan ketidakseragaman diantara ketujuhnya. Nilai frekuensi diri pada tujuh sampel tersebut diambil nilai rata-ratanya $\left(f_{0}\right)$ dan nilai ketidakpastian ralatnya $\left(\Delta f_{0}\right)$ untuk setiap wilahan nada dari wilahan 1 sampai 6 secara berturut-turut yaitu $(209,9 \pm 0,3) \mathrm{Hz},(219,1 \pm 0,5) \mathrm{Hz},(246 \pm 4)$ $\mathrm{Hz},(295 \pm 6) \mathrm{Hz}$, dan $(329,1 \pm 0,3) \mathrm{Hz}$.
\end{abstract}

keywords: frekuensi; bunyi; Gender Barung Laras Slendro; SpectraPlus

\section{Ringkasan}

This research aims to analyze the characteristics frequency of gamelan's sounds, especially Gender Barung Laras Slendro. Gender Barung Laras Slendro is one of gamelan set which does not have standard tone frequency like modern musical instruments. Gamelan tuning is carried out by experts with traditional way, relying on their finesses and senses to match the tones. That method produces asynchronies frequency. The result of this research is expected to create reference in gamelan tone frequency standardization, especially for Gender Barung Laras Slendro. Research is conducted in seven (7) different sampels of Gender Barung Laras Slendro. Self frequency of each wilahan is measured by beat it with a constant relative pressure. The sound are recorded simultaneously by a microphone which is connected with a computer that's equipped with SpectraPlus software. SpectraPlus software will display frequency and spectrum of the sound output. Some collected datas are analized to determine the self frequency value of each wilahan in seven (7) samples of Gender Barung Laras Slendro. The average value is taken from the self frequency values $\left(f_{0}\right)$ and its error value $\left(\Delta f_{0}\right)$ for each wilahan tone from wilahan 1 through 6 are $(209,9 \pm 0,3) \mathrm{Hz},(219,1 \pm 0,5) \mathrm{Hz},(246 \pm 4) \mathrm{Hz},(295 \pm 6) \mathrm{Hz}$, and $(329,1 \pm 0,3) \mathrm{Hz}$.

keywords: frequency; sound; Gender Barung Laras Slendro; SpectraPlus

\footnotetext{
*Korespondensi: mitrayana@ugm.ac.id

Departemen Fisika, Universitas Gadjah Mada, Sekip Utara PO BOX BLS 21, 55281 Yogyakarta, Indonesia

Informasi lengkap tentang penulis dapat dilihat pada akhir artikel

${ }^{\dagger}$ Equal contributor
}

\section{Pendahuluan}

\subsection{Latar Belakang}

Indonesia adalah negara kepulauan dengan berbagai macam suku dan seni budaya termasuk seni musik yang tercipta sebagai sarana berekspresi bagi masyarakat. Salah satu seni musik yang menjadi identitas bangsa Indonesia yaitu gamelan. Di dalam 
Kamus Besar Bahasa Indonesia (1984:251), gamelan didefinisikan sebagai berikut, yaitu: "Seperangkat alat musik Jawa, Sunda, Bali dan lain-lain". Gamelan merupakan salah satu musik tradisional dari Indonesia yang memiliki khas tersendiri dari pembuatannya dan nada atau larasnya [1]. Terdapat dua laras pada gamelan yaitu laras slendro dan laras pelog. Tidak banyak orang yang mampu melakukan pelarasan instrumen musik gamelan. Pelarasan merupakan hal yang sulit dalam pembuatan gamelan karena standard baku laras gamelan tidak ada. Kebanyakan para ahli gamelan hanya mengandalkan pendengarannya dalam melakukan pelarasan nada. Oleh karena itu, dimungkinkan ada perbedaan frekuensi nada antara wilahan yang satu dengan wilahan yang lain.

Perkembangan teknologi dalam dunia komputer menciptakan program-program komputer atau perangkat lunak untuk memudahkan pengukuran besaran-besaran fisis dengan lebih teliti dan akurat. Perkembangan ini memudahkan siapa saja untuk mengkaji secara ilmiah tentang karakteristik bunyi. Dengan demikian dalam penelitian ini memanfaatkan perangkat lunak SpectraPlus dengan analisis Fast Fourier Transform (FFT) untuk mengukur frekuensi diri dari salah satu jenis perangkat gamelan, yaitu Gender Barung Laras Slendro. Dari hasil penelitian yang diberi judul "Pengukuran Frekuensi Bunyi Gender Barung Laras Slendro Menggunakan Perangkat Lunak SpectraPlus" ini nantinya dapat dikembangkan untuk upaya penyeragaman atau standardisasi frekuensi bunyi gamelan.

\section{Dasar Teori}

\subsection{Pengertian Bunyi}

Bunyi yang terdengar merupakan transmisi energi yang melewati media padat, cair dan gas dalam suatu getaran yang diterima telinga dan otak [2]. Perambatan bunyi tersebut sifatnya tergantung pada tingkat transmisi material yang ditentukan oleh ketebalan, konstruksi serta frekuensi.

Pada gelombang bunyi terdapat impedansi akustik yang mempengaruhi pantulan dari gelombang. Impedansi akustik menyebabkan adanya perbandingan amplitudo tekanan dan intensitas gelombang yang telah dipantulkan dan ditransmisikan terhadap gelombang datang. Impedansi akustik $z$ didefinisikan sebagai perbandingan tekanan dalam medium kecepatan partikel medium yang ditunjukkan pada persamaan (1).

$$
z=\frac{p}{u}
$$

dengan $p$ adalah tekanan akustik dan $u$ adalah kecepatan partikel. Impedansi akustik pada gelombang bidang yang menjalar di udara $z=\rho_{0} c$. Bunyi yang menumbuk suatu permukaan akan mengalami berbagai kondisi seperti berikut:

1 Refleksi (pemantulan)

Ketika gelombang suara melalui bidang batas antara dua medium dengan bahan berbeda yang masing-masing memiliki cepat rambat suara yang berbeda maka sebagian energi gelombang suara itu dipantulkan dan sebagian lainnya dibiaskan.

2 Atenuasi

Atenuasi adalah pengurangan intensitas seiring dengan penambahan jarak tempuh yang disebabkan oleh adanya penyerapan dan penghamburan energi oleh medium yang dilewati gelombang.

\subsection{Persamaan Gelombang Bunyi}

Persamaan umum gelombang bunyi dapat diturunkan dari beberapa kombinasi persamaan yaitu persamaan keadaan, persamaan kontinuitas dan persamaan Euler. Penyelesaian umum gelombang satu dimensi dapat dituliskan dalam persamaan (2)

$$
y(x, t)=y_{1}(c t-x)+y_{2}(c t+x),
$$

di mana $y_{1}(c t-x)$ dan $y_{2}(c t+x)$ adalah fungsi bebas dari $(c t-x)$ dan $(c t+x)$. Jika pada fungsi $y_{1}(c t-x)$ dianggap bahwa $w=c t-x$, kemudian turunan parsial pertama terhadap waktu adalah

$$
\frac{\partial y_{1}}{\partial t}=\frac{d y_{1}}{d w} \frac{\partial w}{\partial t}=c \frac{d y_{1}}{d w},
$$

Pengulangan dari diferensial yang berhubungan dengan waktu adalah

$$
\frac{\partial^{2} y_{1}}{\partial t^{2}}=c^{2} \frac{d^{2} y_{1}}{d w^{2}},
$$

selanjutnya

$$
\frac{\partial y_{1}}{\partial x}=\frac{d y_{1}}{d w} \frac{\partial w}{\partial x}=-\frac{d y_{1}}{d w},
$$

dan

$$
\frac{\partial^{2} y_{1}}{\partial x^{2}}=\frac{d^{2} y_{1}}{d w^{2}}
$$

Kombinasi dari persamaan (4), (5), dan (6) menghasilkan persamaan (7):

$$
\frac{\partial^{2} y}{\partial x^{2}}=\frac{1}{c^{2}} \frac{\partial^{2} y}{\partial t^{2}} .
$$


Persamaan gelombang bunyi dapat dituliskan sebagai berikut:

$$
\nabla^{2} p=\frac{1}{c^{2}} \frac{\partial^{2} p}{\partial t^{2}}
$$

atau

$$
\frac{\partial^{2} p}{\partial x^{2}}=\frac{1}{c^{2}} \frac{\partial^{2} p}{\partial t^{2}}
$$

bentuk persamaannya menjadi seperti berikut:

$$
\frac{\partial^{2} p}{\partial x^{2}}+\frac{\partial^{2} p}{\partial y^{2}}+\frac{\partial^{2} p}{\partial z^{2}}=\frac{1}{c^{2}} \frac{\partial^{2} p}{\partial t^{2}} .
$$

dengan $p$ adalah tekanan akustik, $c$ adalah kecepatan termodinamik dari bunyi pada fluida.

\subsection{Pendeteksian Bunyi}

Pendeteksian bunyi perlu konversi dari getaran mekanis gelombang bunyi ke dalam bentuk yang dapat dianalisa frekuensi dan intensitasnya. Di dalam rangkaian, variasi kapasitan menyebabkan variasi waktu pada arus. Komponen arus yang berubah-ubah diamplifikasi secara elektronik, maka arus akan menggerakkan pengeras suara [3].

\subsection{Transformasi Forier}

Bentuk gelombang sinyal pada dasarnya merupakan fungsi waktu di mana analisis yang digunakan adalah analisis Fourier, yang dikembangkan menjadi deret Fourier. $x(t)$ mempunyai penjumlahan gelombang sinusoidal berulang [4], $f_{0}=\frac{1}{T}$,

1 mempunyai frekuensi dasar: $f_{0}=\frac{1}{T}$

$2 \omega=\frac{2 \pi}{T}=2 \pi f_{0}$ adalah frekuensi harmonis pertama,

3 penjumlahan sinyal sinusoidal berulang dapat ditulis:

$$
x(t)=\frac{a_{0}}{2}+\sum_{k=1}^{\infty}\left(a_{k} \cos (\omega n t)+b_{k} \sin (\omega n t)\right)
$$

Penjumlahan tersebut dinamakan deret Fourier dengan $a_{k}, b_{k}$ adalah koefisien frekuensi yang merupakan amplitudo frekuensi.

\subsection{SpectraPlus}

SpectraPlus merupakan software untuk menganalisis sebuah spektrum dengan fitur FFT yang sudah tersedia di dalamnya. SpectraPlus memiliki 3 varian, yaitu RT (Real Time), SC (Sound Card), dan DT (Data Translation). SpectraPlus dapat digunakan sebagai alat untuk analisis spektrum bunyi. Cara kerja SpectraPlus yakni bekerja dengan memanfaatkan soundcard yang ada pada setiap perangkat komputer apabila perangkat lunak ini sudah terinstal.

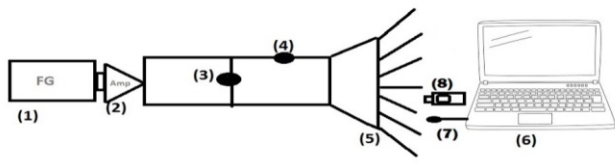

Gambar 1: Skema Kalibrasi Alat (1) Function generator (2) Amplifier (3) Voltmeter (4) Ampermeter (5) Speaker (6) Laptop dilengkapi perangkat lunak SpectraPlus (7) Microphone (8) Sound Level Meter.

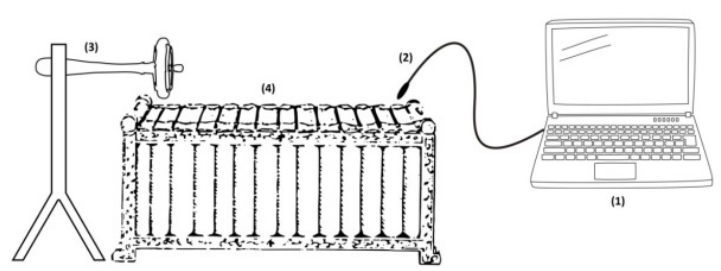

Gambar 2: Skema Pengambilan Data pada Gender (1) Laptop dilengkapi perangkat lunak SpectraPlus (2) Microphone (3) Rangkaian alat tabuh (4) Gender Barung Laras Slendro.

\subsection{Laras}

Laras yaitu sistem penalaan frekuensi dan interval nada-nada gamelan. Apabila dalam sebuah laras terdiri dari 5 (lima) nada maka laras itu disebut sistem 5 nada, apabila 7 (tujuh) nada maka disebut sistem 7 nada, dan seterusnya. Nada-nada tersebut membentuk sebuah sirkel (lingkaran). Jarak satu nada dengan yang lain disebut interval, dalam dunia karawitan disebut dengan istilah sruti [5]. Satuan yang digunakan dalam interval adalah cent.

\section{Metode Penelitian}

\subsection{Alat penelitian}

Peralatan kalibrasi dan peralatan penelitian meliputi perangkat lunak dan perangkat keras, yaitu :

\subsubsection{Kalibrasi}

Kalibrasi dilakukan dengan cara membandingkan data frekuensi yang didapat perangkat lunak SpectraPlus $\left(f_{S P}\right)$ dengan frekuensi pada function generator $\left(f_{f g}\right)$.

\subsubsection{Penelitian pada Gender}

1 Laptop dilengkapi perangkat lunak SpectraPlus

2 Mic Condensor

3 Rangkaian alat tabuh. 


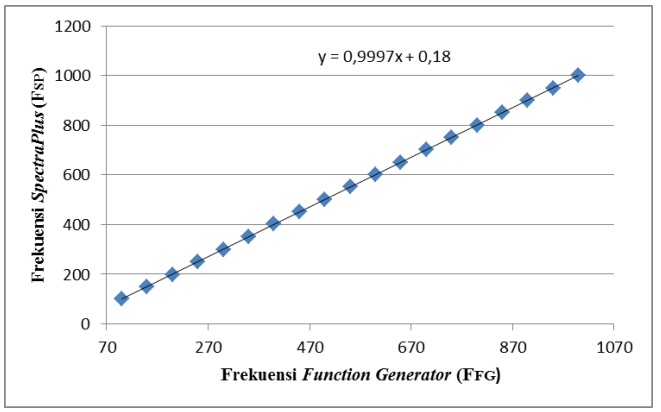

Gambar 3: Hasil Kalibrasi SpectraPlus dengan Function Generator.

\section{Hasil Penelitian dan Pembahasan}

Penelitian karakteristik frekuensi bunyi gender barung laras slendro dilakukan dengan mengunakan 7 set gender barung laras slendro di wilayah DIY. Pemilihan 7 sampel tersebut cukup representatif sebagai bahan penelitian yang mewakili jumlah gamelan yang berada di Nusantara. Setiap sampel dilakukan pengambilan data, baik pada nada rendah maupun nada tinggi.

\subsection{Hasil Kalibrasi}

Data kalibrasi diolah dengan metode regresi linear, diperoleh nilai gradien dan ketidakpastiannya serta nilai titik potong dan ketidakpastiannya sebesar $m \pm$ $\Delta m \approx 0,9997 \pm 0,0007$ dan $c \pm \Delta c \approx(0,18 \pm 0,45)$ $\mathrm{Hz}$.

\subsection{Hasil Penelitian}

Pengambilan data penelitian dilakukan pada tujun gender barung yang berbeda. Setiap gender barung dilakukan pengambilan data dengan proses yang sama. Pengaturan kalibrasi pada SpectraPlus dipastikan tidak berubah dan tetap sama seperti saat dilakukan kalibrasi. Setiap wilahan gender ditabuh dengan cara teknik pukul gembyang yaitu nada yang sama dipukul secara bersamaan. Penabuhan setiap wilahan gender dilakukan sebanyak 45 kali, yaitu 15 kali pukulan di bagian atas, 15 kali pukulan dibagian tengah dan 15 kali pukulan di bagian bawah. Setiap percobaan diperoleh hasil amplitudo yang berbeda namun selisihnya tidak terlalu signifikan. Sedangkan nilai frekuensi yang diperoleh selalu sama. Hal ini membuktikan bahwa seberapa kuat wilahan nada itu ditabuh, frekuensinya akan tetap sama.

\subsection{Perbandingan Hasil Pembahasan dengan Dasar Teori}

Frekuensi setiap nada pada masing-masing gender menunjukan ketidakseragaman. Perbedaan frekuensi ini salah satunya dipengaruhi oleh besar kolom resonator. Kolom resonansi dipengaruhi oleh diameter, panjang, dan ketebalan bahan. Hal ini terlihat pada setiap wilahan gender barung memiliki diameter kolom resonansi yang berbeda. Secara teoritis semakin kecil kolom resonator, akan menghasilkan frekuensi diri yang lebih tinggi. Ini disebabkan karena jarak dinding-dinding di dalam kolom sempit lebih dekat, sehingga pantulan getaran udara lebih sempurna, udara di dalam cepat mampat, kerapatannya lebih besar dan gelombang bergetar lebih cepat sehingga menimbulkan gelombang bunyi dengan frekuensi yang tinggi. Namun terdapat sampel yang tidak sesuai dengan teori ini, seperti pada sampel di UKM Kamasetra UNY. Diameter pada nada 1 (untuk nada rendah dan nada tinggi) lebih besar daripada nada 3, 5, dan 6 namun nada 1 memiliki frekuensi yang lebih besar jika dibandingkan dengan ketiga nada tersebut. Hal ini bisa saja terjadi karena nilai frekuensi tidak hanya bergantung pada kolom frekuensi. Ukuran dan ketebalan bilah gender mempengaruhi besar frekuensi. Semakin kecil keliling dan ketebalan bilah gender, berarti semakin kecil pula luasan permukaannya. Semakin kecil luasan permukaannya maka akan menghasilkan frekuensi yang lebih tinggi. Hal tersebut membuktikan bahwa frekuensi diri $\left(f_{0}\right)$ berbanding terbalik dengan luasannya $(L)$. Selain itu perbedaan frekuensi juga dipengaruhi oleh banyaknya proses pelarasan yang sudah dilakukan. Melaras yaitu meninggikan atau merendahkan nada dengan cara mengeruk bagian tengah bilah untuk meninggikan nada dan mengeruk bagian tepi bilah untuk merendahkan nada. Tujuan dilakukannya pelarasan yaitu agar nada yang diciptakan dari gender tersebut tetap terjaga harmonisasinya dan enak didengar. Hasil frekuensi setiap laras dari masing-masing gender kemudian dirata-rata sehingga diperoleh nilai rata-rata frekuensi diri dan ketidakpastiannya sebagai berikut: Nada $1 f_{0} \pm \Delta f_{0}=(209,9 \pm 0,3) \mathrm{Hz}$; Nada $2 f_{0} \pm \Delta f_{0}=(219,1 \pm 0,5) \mathrm{Hz}$; Nada 3 $f_{0} \pm \Delta f_{0}=(246 \pm 4) \mathrm{Hz}$; Nada $5 f_{0} \pm \Delta f_{0}=(295 \pm 6)$ Hz; Nada $6 f_{0} \pm \Delta f_{0}=(329,1 \pm 0,3) \mathrm{Hz}$.

Spektrum yang dihasilkan setiap gender barung laras slendro 1 diketahui mencapai amplitudo maksimum rata-rata antara 50,01 sampai 76,65 dB. Spektrum yang dihasilkan setiap gender barung laras slendro 2 diketahui mencapai amplitudo maksimum rata-rata antara 52,14 sampai 78,31 dB. Spektrum yang dihasilkan setiap gender barung laras slendro 3 diketahui mencapai amplitudo maksimum rata-rata antara 55,85 sampai 79,65 dB. Spektrum yang dihasilkan setiap gender barung laras slendro 5 diketahui mencapai amplitudo maksimum rata-rata 


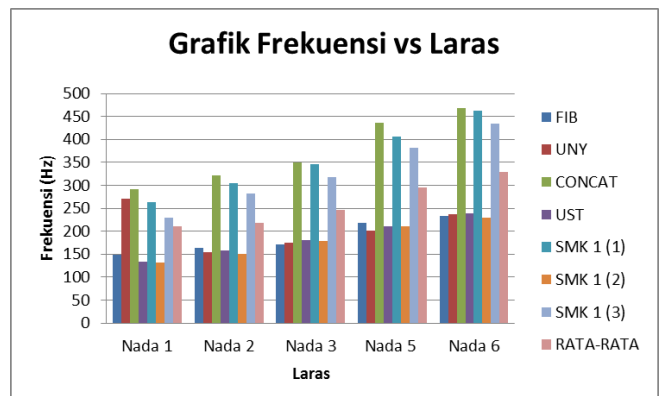

Gambar 4: Grafik Hubungan Antara Frekuensi dengan Laras.

antara 57,65 sampai 81,54 dB. Spektrum yang dihasilkan setiap gender barung laras slendro 6 diketahui mencapai amplitudo maksimum rata-rata antara 52,78 sampai 81,22 dB. Rentang yang tidak terpaut jauh tersebut menunjukkan penabuhan dilakukan dengan tekanan pukulan yang relatif tetap. Setiap penabuhan akan memberikan tenaga pada gender untuk bergetar. Getaran tersebut akan menggetarkan udara di dalam kolom resonatornya dan berlangsung agak lama. Amplitudo getaran tersebut semakin lama akan semakin berkurang, tetapi frekuensinya tetap. Lama dan cepatnya getaran tersebut berhenti akan mempengaruhi karakter spektrum setiap wilahan.

Gambar 4 menunjukan perbandingan frekuensi nada untuk ketujuh jenis gender barung yang digunakan.

\section{Kesimpulan}

Berdasarkan ini dapat disimpulkan bahwa:
1 Nilai rata-rata frekuensi diri dan nilai ketidakpastian setiap nada pada ketujuh gender barung laras slendro yaitu:

(a) Nada $1 f_{0} \pm \Delta f_{0}=(209,9 \pm 0,3) \mathrm{Hz}$

(b) Nada $2 f_{0} \pm \Delta f_{0}=(219,1 \pm 0,5) \mathrm{Hz}$

(c) Nada $3 f_{0} \pm \Delta f_{0}=(246 \pm 4) \mathrm{Hz}$

(d) Nada $5 f_{0} \pm \Delta f_{0}=(295 \pm 6) \mathrm{Hz}$

(e) Nada $6 f_{0} \pm \Delta f_{0}=(329,1 \pm 0,3) \mathrm{Hz}$

2 Faktor penyebab perbedaan frekuensi diri setiap wilahan adalah besar kolom resonator yang tergantung dari keliling dan ketebalan bilahnya karena semakin kecil kolom resonator maka frekuensi yang dihasilkan semakin tinggi.

3 Karakter spektrum bunyi Gender Barung Laras Slendro pada penelitian ini menunjukkan rata-rata amplitudo maksimum dicapai pada $(50,01-82,23)$ dB pada jangkauan frekuensi $(131,84-468,75) \mathrm{Hz}$.

\section{Pustaka}

1. Kuswanto, H., dkk: Pengembangan Desain Electronic Tone Gamelan Jawa Standar Sebagai Seni Yang Mendukung Industri Kreatif Serta Model Pelestarian Local Genius Melalui Aplikasi Teori Akustik Spektrum Vibrasi. Laporan Penelitian Strategi Nasional UNY, Yogyakarta (2009)

2. Kinsler, L.E., Frey, R.A.: Fundamental of Acoustic. John Willey \& Sons, New York (1958)

3. Cytasari, V.J.: Pengukuran Frekuensi Bunyi Saron Demung Laras Pelog Gamelan Jawa Menggunakan Perangkat Lunak Visual Analyser

4. Sitanggang, Doni, Sumardi, Hidayanto, A. (eds.): Pengenalan Vocal Bahasa Indonesia Dengan Jaringan Syaraf Tiruan Melalui Transformasi Fourier. Simposium Nasional I, RAPI, Jakarta (2002)

5. Hendarto, Hastanto, S.: Organologi Dan Akustika I Dan

II. Lubuk Agung, Bandung (2011) 